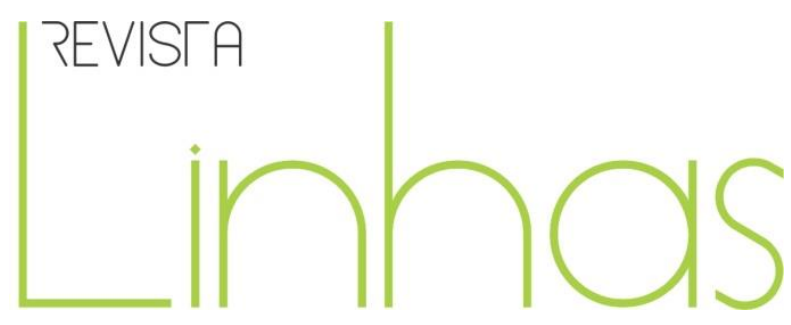

\title{
Objetos de aprendizagem: um panorama da produção acadêmica nacional
}

\section{Resumo}

Os estudantes das novas gerações que frequentam as instituições escolares podem ser considerados nativos digitais, pois nasceram em uma era digital e desde a infância interagem com recursos tecnológicos variados. Nesta perspectiva, faz-se necessário buscar conhecimentos e estratégias pedagógicas para a incorporação de recursos tecnológicos, como os Objetos de Aprendizagem (OA) no contexto educacional. Este estudo teve por objetivo realizar uma revisão de literatura, considerando dissertações e teses, sobre OA, com o intuito de identificar as principais temáticas abordadas nas produções, o status jurídico, o tipo e o ano de publicação. Para tanto, realizamos pesquisa bibliográfica na Biblioteca Digital Brasileira de Teses e Dissertações, por meio do descritor "objetos de aprendizagem". Com base nas produções acadêmicas encontradas, verificamos que entre os anos de 2003 e 2016 foram publicadas 168 teses e dissertações, que foram divididas em 27 categorias temáticas, sendo que as predominantes foram Engenharia de Software, Ensino de Matemática, Ensino Superior, Ensino de Física e Repositórios. Em relação ao nível de ensino, constatamos que a maioria das produções encontradas são dissertações de mestrado, e que o maior número de produções defendidas concentra-se nas instituições de ensino federais. Embora reconheçamos que são necessárias investigações sobre interface, usabilidade e linguagem de programação, defendemos que não basta termos recursos excepcionais do ponto de vista tecnológico, se os professores não forem capacitados para utilizar os mesmos, sendo que boa parte dos que atuam na educação básica não apresentam conhecimentos necessários para utilizar $\mathrm{OA}$ e demais tecnologias digitais de maneira intencional e produtiva.

Palavra-chave: Revisão de Literatura. Objetos de Aprendizagem. Produções Acadêmicas. Tecnologia Educacional.

\section{Ketilin Mayra Pedro}

Universidade do Sagrado

Coração - Bauru/SP - Brasil

ketilinp@yahoo.com.br

\section{Dariel Carvalho}

Consultor educacional na área de tecnologia - Bauru/SP - Brasil prof.darielcarvalho@gmail.com

\section{Para citar este artigo:}

PEDRO, Ketilin Mayra; CARVALHO, Dariel. Objetos de aprendizagem: um panorama da produção acadêmica nacional. Revista Linhas. Florianópolis, v. 19, n. 40, p. 414-433, maio/ago. 2018. 


\title{
Learning objects: a panorama of national academic production
}

\begin{abstract}
Students of the new generations attending school institutions can be considered digital natives, since they were born in a digital age, because they were born in a digital era and since their childhood interacting with varied technological resources. In this perspective, it is necessary to seek knowledges and pedagogical strategies for the incorporation of technological resources, such as the Learning Objects $(\mathrm{OA})$ in the educational context. This study aimed to perform a literature review, considering dissertations and theses about OA, with the purpose of identifying the main topics addressed in the productions, legal status, type and year of publication. To do so, we perform a bibliographic research in the Brazilian Digital Library of Theses and Dissertations through the descriptor learning objects. Based on the academic productions found, we verified that between the years 2003 and 2016, 168 theses and publications were published, wich were divided into 27 thematic categories, the predominant ones being Software Engineering, Mathematics Teaching, Higher Education, Physics Teaching and Repositories. Regarding the level of education, we found that most of the productions found are master's dissertation, and that the largest number of productions defended are concentrated in federal educational institutions. Although we recognize that there is a need for research on interface, usability and programming language, we argue that it is not enough to have exceptional resources from a technological point of view if teachers are not qualified to use them, and a good part of the teachers who work in a basic education do not have the necessary knowledge to use $O A$ and other digital Technologies in an intentional and productive manner.
\end{abstract}

Keywords: Literature Review. Learning Objects. Academic Productions. Educacional Technology. 


\section{Introdução}

As Tecnologias Digitais da Informação e Comunicação (TDIC) e a internet revolucionaram o modo como nos relacionamos, estudamos, viajamos, compramos e, consequentemente, todo o cenário mundial. Castells (2003, p. 7) afirma que "a internet é o tecido de nossas vidas", devido a sua capacidade de interatividade e distribuição da informação.

Embora as inovações causadas pelas TDIC tenham atingido vários setores da sociedade, observamos que é nos espaços escolares que esses recursos ainda são subutilizados, seja pela falta de estratégias educacionais que promovam uma boa utilização desse recurso, infraestrutura inadequada para instalação e uso das TDIC ou por conta da deficitária formação específica da equipe escolar.

As novas gerações que frequentam as instituições escolares, atualmente, podem ser consideradas como nativos digitais, pois nasceram em uma era digital e desde a infância interagem com recursos tecnológicos variados. Segundo estudiosos da área, estes estudantes apresentam habilidades diferenciadas em relação à tecnologia, principalmente na exploração de recursos de internet como jogos, redes sociais, aplicativos de mensagem instantânea etc. (GATTI, 2005; MATTAR, 2010; PALFREY; GASSER, 2011; PESCADOR, 2012; LAGARTO, 2013).

Nesta perspectiva, faz-se necessário buscar conhecimentos e estratégias pedagógicas para a incorporação das TDIC nos currículos escolares. Diante dos variados tipos de recursos tecnológicos que podem ser utilizados no contexto educacional, destacaremos, neste trabalho, os Objetos de Aprendizagem (OA). Existem diversas definições para OA, sendo que Willey (2000) considera objetos de aprendizagem qualquer recurso digital que possa ser reutilizado para apoiar a aprendizagem.

Segundo Aguiar e Flôres (2014), os OA caracterizam-se como ferramentas de aprendizagem e instrução que podem ser utilizadas no ensino de qualquer conteúdo didático, desde que o professor utilize estes recursos com intencionalidade e selecione aqueles que melhor correspondem aos seus objetivos educacionais dentro de um determinado conteúdo e faixa etária. 
Os OA são apontados constantemente na literatura como um recurso facilitador para o processo de ensino-aprendizagem (CARNEIRO; SILVEIRA, 2014; RODRIGUES; BEZ; KONRATH, 2014; BARBERÀ; ROCHERA, 2010), no entanto, faz-se necessário investigar de que maneira estes recursos têm sido produzidos, aplicados e pesquisados na realidade nacional.

Diante do exposto, observa-se a necessidade de conhecer as produções acadêmicas sobre a temática dos $\mathrm{OA}$, com o objetivo de revisar de maneira crítica e sistemática as pesquisas científicas publicadas. Omote (2014) evidencia a importância de pesquisas que visem à revisão de literatura. Segundo o autor, diante do vasto volume de publicações disponíveis, nas mais variadas bases de dados, torna-se pertinente revisar amplamente a literatura, com o intuito de verificar os temas mais pesquisados dentro de uma determinada área e aqueles que necessitem de maior estudo e sistematização.

Desta maneira, o objetivo desta pesquisa constituiu-se em realizar uma revisão de literatura, considerando dissertações e teses, sobre Objetos de Aprendizagem, com o intuito de identificar as principais temáticas abordadas nas produções, o status jurídico, o tipo e o ano de publicação.

\section{Método}

A trajetória metodológica deste trabalho iniciou-se com uma pesquisa bibliográfica na Biblioteca Digital Brasileira de Teses e Dissertações (BDTD). Este repositório de produções acadêmicas é mantido pelo Instituto Brasileiro de Informação em Ciência e Tecnologia (IBICT) e reúne teses e dissertações de instituições de ensino de todo o país, destacando-se como uma das maiores iniciativas brasileiras na divulgação destas produções.

Para a realização do levantamento das produções, foram utilizados o descritor objetos de aprendizagem, sendo que foram encontradas inicialmente 190 produções e, ao final da busca, constatamos que apenas 168 versavam sobre a temática pesquisada.

Após a realização da pesquisa na BDTD, organizamos as teses e dissertações encontradas e elencamos categorias temáticas, a fim de agrupar as pesquisas que versavam sobre o mesmo tema. Esta categorização foi realizada com base no título, 
palavras-chave e resumo de cada uma das produções. Além da categorização temática, realizaram-se agrupamentos de acordo com o ano de publicação, o tipo de produção e o status jurídico.

\section{Resultados e discussões}

Com base no levantamento bibliográfico realizado, localizamos um total de 168 produções, sendo 130 dissertações e 38 teses, defendidas no intervalo temporal de 2003 a 2016. A análise das produções acadêmicas propiciou a categorização do tema, ano de publicação, número de teses/dissertações e a distribuição entre as universidades federais, estaduais e particulares.

A Figura 1 apresenta a distribuição das teses e dissertações por ano de publicação.

Figura 1 - Distribuição das produções acadêmicas por ano de publicação.

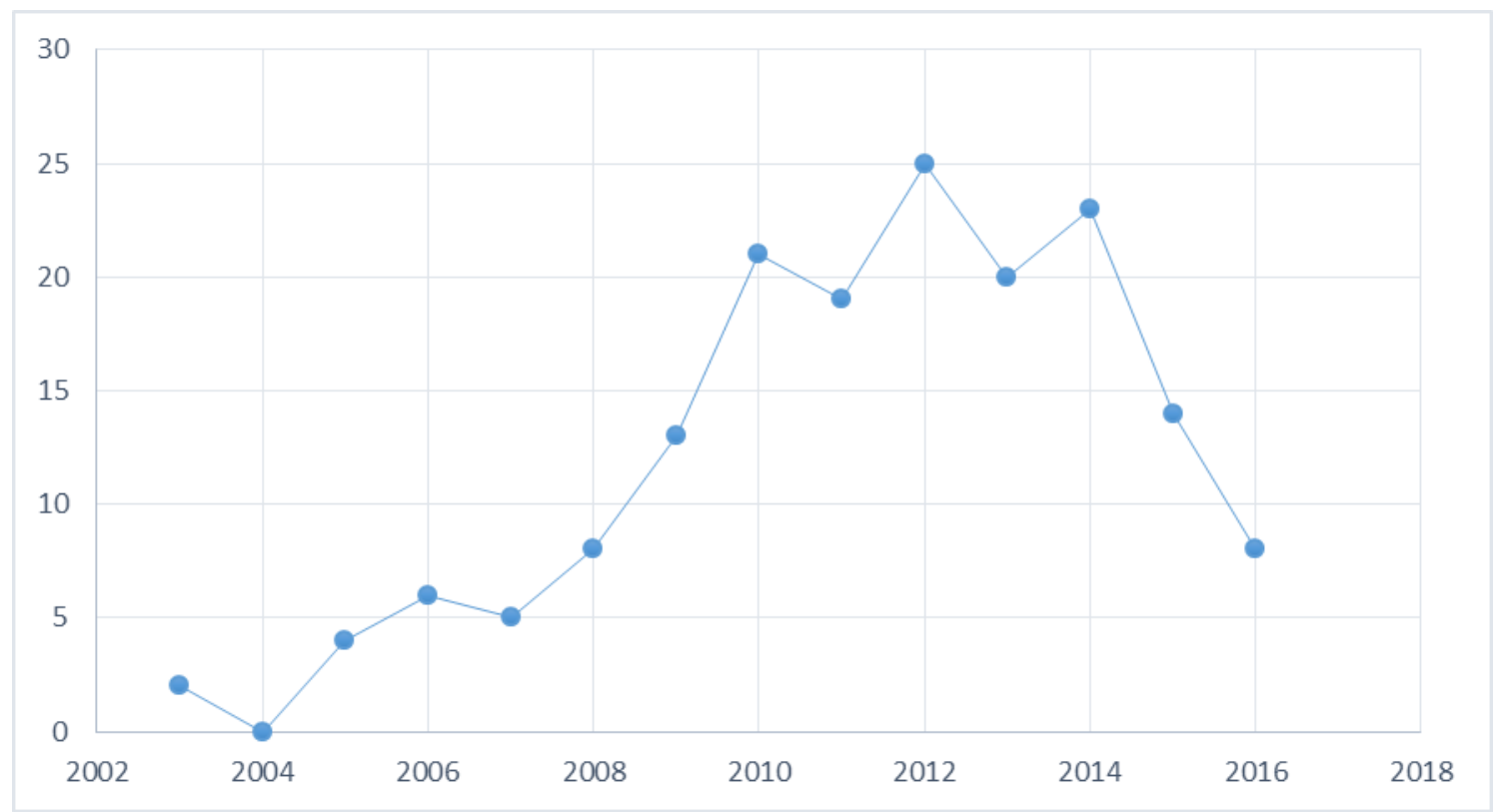

Fonte: Elaboração própria. 
As produções acadêmicas encontradas foram defendidas entre os anos de $2003 \mathrm{e}$ 2016, sendo possível observar um crescimento significativo no número de dissertações e teses defendidas nos últimos cinco anos. Ao analisar a literatura, observamos que o conceito de OA começa a ser definido e discutido a partir dos anos 2000 (WILLEY, 2000), o que justificaria o fato de termos encontrado as primeiras publicações no ano de 2003.

O ano de 2008 é marcado pela criação do Portal do Professor e do Banco Internacional de Objetos Educacionais (BIOE), ambos foram iniciativas do Ministério da Educação, com o objetivo de promover a inclusão digital do professor, de maneira que este conheça recursos tecnológicos que podem ser explorados no contexto da sala de aula (BALAN et al., 2010). Acredita-se que a criação destes portais motivou a realização de mais pesquisas na área, sendo que a partir do referido ano, observa-se um aumento crescente no número de publicações. Ressalta-se que como a coleta de dados foi realizada no segundo semestre de 2016, mais produções podem ter sido defendidas até o final do referido ano.

Para realizar a categorização da temática das produções acadêmicas, foi analisado o título, o resumo e as palavras-chave. As teses e dissertações encontradas foram agrupadas em 27 categorias temáticas sendo elas: Alfabetização, Aprendizagem Colaborativa, Artefatos Pedagógicos, Avaliação de Objetos de Aprendizagem, Design, Educação a Distância, Educação Ambiental, Educação Especial, Empresarial, Engenharia de Software, Ensino de Ciências, Ensino de Física, Ensino de Geografia, Ensino de História, Ensino de Idiomas, Ensino de Lógica, Ensino de Matemática, Ensino de Música, Ensino Híbrido, Ensino Médio, Ensino Superior, Formação de Professores, Letramento Digital, Processo de Ensino-Aprendizagem, Repositórios, Saúde e TV Digital. A Figura 2 apresenta a distribuição das produções acadêmicas por categoria temática. 
Figura 2 - Distribuição das produções acadêmicas por categoria temática.

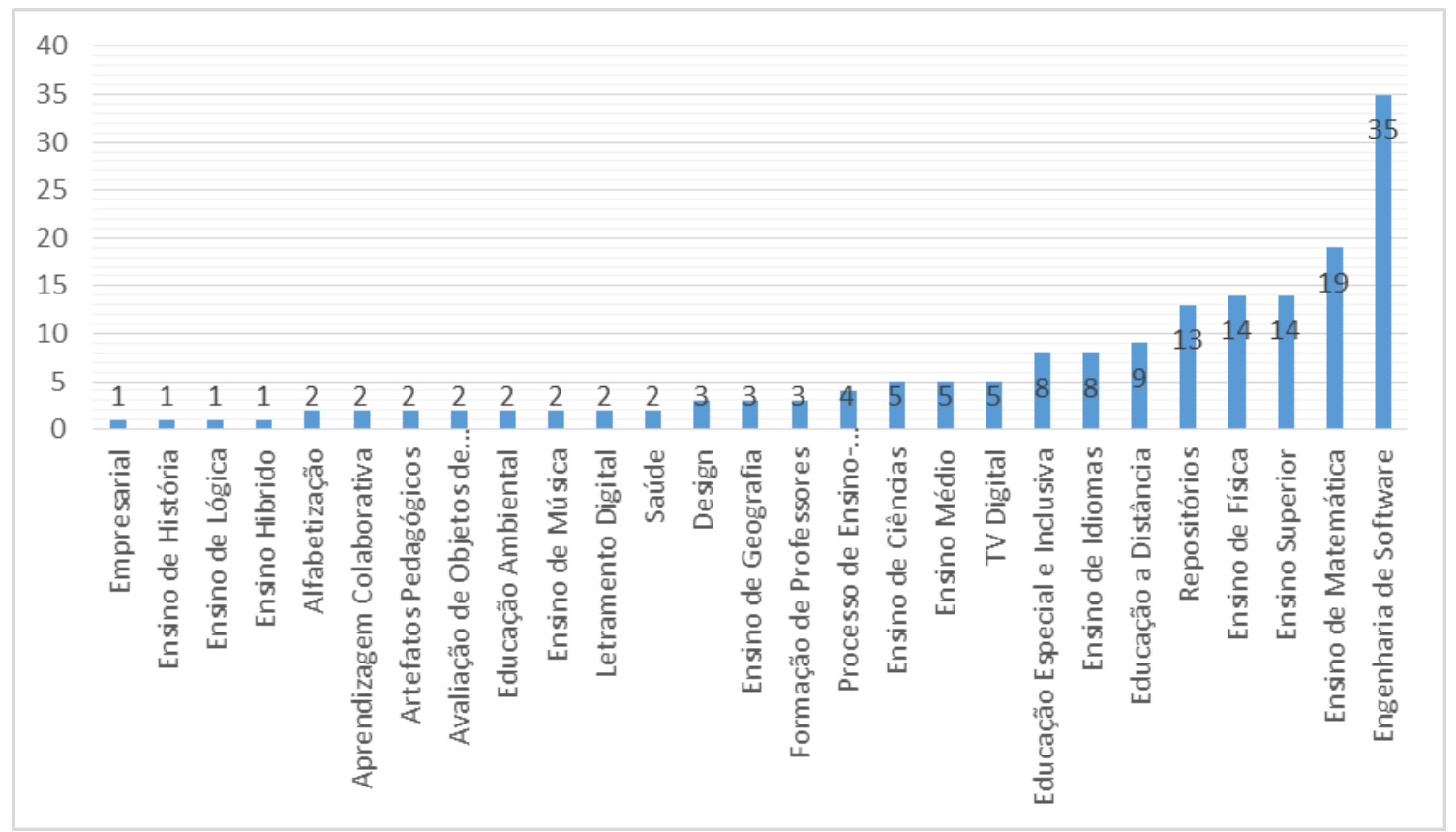

Fonte: Elaboração própria.

Ao analisar a figura apresentada anteriormente, observa-se que algumas categorias temáticas não possuem um número de produções acadêmicas significativo, apontando que estes temas ainda não são amplamente discutidos e estudados dentro da universidade e da educação básica.

Destaca-se, inicialmente, as categorias Ensino de História, Ensino de Lógica, Alfabetização, Educação Ambiental, Ensino de Música e Ensino de Geografia. Ao considerarmos as disciplinas que compõem o currículo escolar, observamos que apenas aquelas disciplinas apontadas como difíceis e que necessitam de experimentos e objetos concretos (como matemática, física e ciências), para que o estudante aprenda de maneira significativa, são consideradas nas pesquisas que utilizam $O A$. A literatura aponta que o processo de ensino-aprendizagem de todas as disciplinas pode ser enriquecido e aprimorado por meio da utilização de OA (SILVA; CAFÉ; CATAPAM, 2010; DAMACENO; SANTOS, 2013; BULEGON; MUSSOI, 2014). Acredita-se que a escassez de OA relacionados a estas disciplinas pode ter acarretado um menor número de pesquisas que contemplem estas áreas. 
Apenas uma produção acadêmica foi alocada na categoria temática Ensino Híbrido, demonstrando que embora as metodologias ativas ${ }^{1}$ venham ganhando destaque em congressos, cursos e publicações, o número de estudos que articulam a utilização de OA e estas metodologias ainda são incipientes. Segundo Moran (2015), os métodos tradicionais de ensino faziam sentido quando a informação não estava ao alcance de todos. Atualmente, com a popularização da internet, os estudantes podem acessar qualquer conteúdo com apenas alguns cliques, demonstrando a necessidade da escola propor metodologias em que o estudante acesse o conteúdo em casa e vá para a escola com o objetivo de problematizar, discutir e realizar atividades criativas e produtivas. $\mathrm{O}$ ensino híbrido, especificamente, caracteriza-se como uma metodologia em que atividades presenciais e online se misturam, sendo que o estudante deve realizar as atividades de cunho mais teórico em uma plataforma, site ou ambiente digital e a sala de aula será espaço para aplicar e desenvolver os conteúdos estudados previamente (CHRISTENSEN, 2012).

As categorias temáticas relacionadas à avaliação de OA e Design, embora não tenham um significativo número de produções, representam temas importantes de serem pesquisados para que possamos aprimorar cada vez mais a usabilidade dos OA e ofertar interfaces dinâmicas e funcionais aos seus usuários. De acordo com Lima et al. (2007), interfaces bem elaboradas permitem que o usuário explore com facilidade o OA. Ainda segundo os autores, aliar usabilidade e design adequado é um dos grandes desafios na construção de OA. Quanto à avaliação dos objetos, Reategui, Boff e Finco (2010) destacam que os aspectos pedagógicos e técnicos devem ser observados com atenção, para que tenhamos OA coerentes do ponto de vista curricular e funcionais em relação à estética, interatividade e navegação.

Aprendizagem Colaborativa e Letramento Digital são categorias temáticas que se relacionam com as discussões referentes à Cultura Digital e Sociedade da Informação e do Conhecimento. Estudiosos da área afirmam que em uma era em que notícias, conteúdos e variadas mídias são postadas e atualizadas a todo o momento, a aprendizagem acontece cada vez mais de maneira colaborativa, uma vez que, podemos

\footnotetext{
1 Caracteriza-se como metodologia ativa práticas pedagógicas que estão centradas no estudante, colocando-o no papel de protagonista do processo de ensino-aprendizagem (ARAUJO, 2015).
} 
editar, compartilhar e postar infinitos conteúdos na internet e, consequentemente, construir novas redes de saberes (LÉVY, 1999; BARROS; BRIGHENTI, 2004; GÓMEZ, 2015). Autores como Buim Arena (2015), Santaella (2004), Beluzzo e Feres (2011) afirmam que a influência das TDIC e da cultura digital são percebidas em relação à leitura, já que atualmente fazemos, sobretudo quando estamos diante de textos digitais, uma leitura mais interativa, que geralmente não segue uma ordem linear, mas é alterada de acordo com o interesse e a necessidade do leitor, características estas que requerem novas estratégias de leitura e escrita que compreendem o universo do Letramento Digital.

A categoria temática Formação de Professores agregou apenas três produções acadêmicas; entretanto, considera-se esta temática de suma importância para que possamos progredir na utilização dos recursos tecnológicos no contexto educacional. Segundo Aguiar e Flôres (2014) cabe ao professor selecionar, avaliar e atribuir intencionalidade pedagógica aos OA que serão utilizados no contexto da sala de aula. Para tanto, é necessário que o professor tenha conhecimentos básicos sobre tecnologia e reconheça a necessidade e a importância de utilizar as TDIC no contexto educacional, uma vez que, quando estes recursos são selecionados e utilizados de maneira adequada, proporcionam motivação e enriquecem o processo de ensino-aprendizagem dos estudantes (BARROS; BRIGHENTI, 2004; SANTAROSA; CONFORTO, 2012). Nessa perspectiva, consideramos de suma importância oferecer formação específica para os professores, para que estes se tornem competentes digitalmente e utilizem os recursos tecnológicos de maneira criativa e produtiva em sala de aula. Autores como Almeida (2000), Altoé e Fugimoto (2009) apontam que a formação de professores em relação aos recursos tecnológicos é imprescindível frente ao avanço digital dos últimos anos. Sendo assim, consideramos condição sine qua non, para aqueles que pretendem ser ou manterem-se professores, formação específica na área e superação das barreiras atitudinais em relação à utilização das TDIC.

As categorias temáticas Ensino de Ciências, Ensino Médio e TV Digital ${ }^{2}$ contaram com cinco produções acadêmicas cada. Sobre o ensino de ciências, observa-se que é uma

\footnotetext{
${ }^{2}$ TV digital se refere à transmissão de sinais de TV em um formato digital. A transmissão digital permite mesclar conteúdos de áudio e vídeo com dados. Assim, é possível entregar aplicações de software em um aparelho digital de TV ou em um receptor digital. O receptor é necessário para receber o sinal digital usando um sintonizador digital e, então, convertê-lo para um formato analógico para ser visto em um aparelho
} 
área com vários $\mathrm{OA}$ disponíveis em repositórios, que se justifica pelo fato de ser um componente curricular que possibilita a realização de variados experimentos, sendo que os recursos de tecnologia possibilitam a visualização e interação com variados fenômenos que, se desenvolvidos apenas de maneira teórica, tornam-se conteúdos muito abstratos e não despertam o interesse dos estudantes (SABBATINI, 2012).

A categoria Ensino Médio pode ser discutida com base nos apontamentos que os teóricos da área fazem a respeito do modo como os jovens do século XXI interagem com as TDIC. Autores como Veen e Vrakking (2009) destacam que as crianças e os adolescentes nascidos na era digital, em sua maioria, irão apresentar características como atenção limitada (restrita a pequenos intervalos de tempo), comportamento hiperativo e dificuldade para concentrar-se em aulas totalmente expositivas, visto que estes estão acostumados a interagir em ambientes interativos, dinâmicos e com diversas mídias integradas, considerando tediosas as atividades que não trazem interação e dinamismo. Nesta perspectiva, é cada vez mais necessário inserir recursos de tecnologia, como os OA, no processo de ensino-aprendizagem dos estudantes de nível médio; uma utilização competente e consciente destes recursos, por meio de metodologias ativas de ensino que proporcionam maior protagonismo e envolvimento do estudante nas práticas escolares.

A TV digital vem ganhando destaque em discussões sobre a área tecnológica, desde o ano de 2006, quando foi publicado o decreto sobre a implementação do Sistema Brasileiro de Televisão Digital Terrestre. Desde então, há um movimento de substituições de equipamentos de TV para que sejam capazes de capturar o sinal digital. Estudiosos da área acreditam que a TV digital poder ser explorada além da finalidade do entretenimento, mas também com finalidades sociais, tornando-se uma promessa na área tecnológica. Ao longo dos anos, houve iniciativas, como a TV escola e o Telecurso 2000, para utilizar este equipamento como recurso pedagógico, Acredita-se que a utilização de OA por meio das TVs digitais poderá proporcionar novas oportunidades de aprendizagem, denominada por alguns teóricos como t-learning (GOMES; LIMA; NEVADO, 2009; LIMA et al., 2013).

analógico de TV. O receptor pode estar embutido em um aparelho digital de TV ou ser um equipamento à parte (GOMES; LIMA; NEVADO, 2009, p. 2). 
A temática da Educação Especial e Inclusiva apareceu em oito produções acadêmicas. Ao analisar as produções alocadas nesta categoria, observou-se que os enfoques utilizados foram variados, uma vez que se encontraram produções sobre deficiência visual, auditiva, autismo, sala de recursos multifuncionais, formação de professores e qualidade dos materiais educacionais para a educação especial e inclusiva. Para Peres e Petitto (2012), o professor precisa empregar alternativas diferenciadas que atendam as individualidades dos estudantes público-alvo da educação especial, sendo que os recursos de tecnologia podem melhorar a oferta do atendimento educacional especializado para estes estudantes. A utilização de OA para estudantes público-alvo da educação especial proporciona acesso, adaptação e enriquecimento no processo de ensino-aprendizagem (OLIVEIRA; GASPARETTO, 2013).

A categoria Ensino de Idiomas alocou oito produções acadêmicas. A utilização de recursos tecnológicos no ensino de idiomas ganha cada vez mais destaque no cenário educacional, uma vez que estes recursos possibilitam que os estudantes exercitem diferentes habilidades: escrita, conversação e compreensão. Leffa (2006) destaca que os OA ainda são subutilizados dentro do ensino de idiomas, sendo necessária uma maior divulgação e produção destes recursos para que sua utilização aconteça de maneira cada vez mais frequente.

O tema Educação a Distância foi destacado em nove produções. Os enfoques encontrados nestas pesquisas foram variados, contemplando desde a interação dos usuários com os OA em plataformas virtuais até a formação de professores para atuar com estes recursos. De acordo com Paulo, Ribas e Knaut (2015, p. 1) os OA “têm sido um dos materiais didáticos mais utilizados no processo de ensino-aprendizagem da Educação a Distância, permitindo a interação e a estimulação de novos conhecimentos". Carneiro e Silveira (2014) corroboram com esta afirmação e reconhecem os OA como elementos facilitadores da Educação a Distância; dessa maneira, é necessária a realização de pesquisas nesta área para que possamos otimizar a utilização destes recursos em todos os ambientes, inclusive os virtuais, desenvolvendo e aprimorando assim as iniciativas de educação a distância em nosso país.

A categoria temática Repositórios alocou 13 produções acadêmicas. Atualmente, há, disponíveis na internet, variados repositórios mantidos pelo Ministério da Educação, 
universidades e institutos, tais como: Banco Internacional de Objetos Educacionais (BIOE), Portal do Professor, Rede Interativa Virtual de Educação (RIVED), Livre Saber Repositório Digital de Materiais Didáticos entre outros. De acordo com Schmitt et al. (2013), os repositórios podem ser considerados como catálogos digitais que têm por objetivo reunir OA sobre os mais variados temas e níveis de ensino. As ferramentas de busca e os filtros otimizam a pesquisa e direcionam os resultados de acordo com a necessidade de cada usuário. As produções acadêmicas alocadas nesta categoria versavam principalmente sobre a criação de repositórios, integração destes com ambientais virtuais de aprendizagem e aperfeiçoamento das ferramentas de busca. Acredita-se que o aprimoramento dos repositórios, seus filtros e ferramentas de pesquisa facilitam a interação dos professores neste site, e tornam a utilização mais funcional e produtiva.

As categorias temáticas Ensino de Física e Matemática tiveram 14 e 19 produções, respectivamente, e por tratarem de dois componentes da área das ciências exatas, a discussão destes dados foi realizada de maneira conjunta. Segundo o estudo de Melo e Silva (2011), a maioria dos professores, da educação básica, da área de exatas não foram formados, em nível de graduação, para utilizar estratégias pedagógicas diferenciadas durante suas aulas. Geralmente, estes utilizam poucos recursos e realizam um uso excessivo do livro didático. Aguiar e Flôres (2014) enfatizam que a utilização de recursos tecnológicos e de OA favorece a compreensão e aplicação de conceitos complexos, além de propiciar a manipulação e observação de efeitos que não seriam possíveis sem o uso da tecnologia. A maioria das produções, de ambas as categorias, enfocavam a criação e aplicação de $\mathrm{OA}$ em contextos educativos. Acredita-se que o desenvolvimento de pesquisas e a divulgação de recursos deste tipo podem estimular a utilização frequente destes por parte dos professores, lembrando que para tanto, estes precisam ser instrumentalizados para que possam selecionar e planejar a utilização dos OA de maneira adequada.

Quatorze produções acadêmicas foram categorizadas em Ensino Superior. Os enfoques destas pesquisas estavam direcionados para o desenvolvimento e aplicação de OA e a integração destes com ambientais virtuais de aprendizagem. Segundo Cordenonsi e Bernardi (2010), as metodologias ativas de ensino e utilização de OA podem 
transformar a sala de aula em um espaço para o diálogo e questionamentos, retirando o estudante de nível superior da condição de agente passivo, tornando-o protagonista do próprio processo de ensino-aprendizagem.

A categoria temática com maior número de produções acadêmicas foi a de Engenharia de Software, sendo que está representa 21\% do total das teses e dissertações encontradas. Foram alocadas nesta categoria todas as pesquisas que enfocavam a criação e otimização dos OA. De acordo com Geller, Sobrinho e Araujo (2010) a área de engenharia de software proporciona uma estrutura para a organização das ações para o desenvolvimento de softwares e OA, que possibilitam a criação de recursos funcionais que atendam às especificidades de seus usuários. Embora reconheçamos que as pesquisas nesta área contribuem para o aprimoramento dos $\mathrm{OA}$, chamamos a atenção para o fato de que necessitamos de pesquisas que apontem direcionamentos para a utilização destes recursos; precisamos investigar quais são as dificuldades encontradas pelos professores para utilizá-los e de que maneira podemos viabilizar uma utilização adequada e intencional do OA no processo de ensino-aprendizagem.

Quanto ao tipo de produção acadêmica encontrada, observa-se que a maioria das pesquisas refere-se a dissertações de mestrado (130 - 77\%), enquanto 38 produções são teses de doutorado. De acordo com os dados do Sistema de Informações Georreferenciadas da Coordenação de Aperfeiçoamento Pessoal de Nível Superior GEOCAPES (CAPES, 2015) existem no Brasil, atualmente, 2031 programas que contemplam a formação de mestres e doutores, 1207 programas de mestrado e 603 programas de mestrado profissional, sendo que estes concentram-se, majoritariamente, nos estados de Minas Gerais, Rio de Janeiro, São Paulo, Bahia, Paraná e Rio Grande do Sul. Dessa maneira, pode-se observar que os nossos dados convergem com as estatísticas da CAPES, uma vez que, há mais programas de mestrado e que a duração destes cursos é menor do que os de doutorado, o que acarreta um maior número de produções defendidas em um determinado período. Há que se mencionar também as especificidades dessas duas modalidades, de modo que no mestrado o pesquisador está iniciando no universo da pesquisa, enquanto no doutorado espera-se que o pesquisador produza algo inédito e que traga grandes contribuições para a área pesquisada.

A Figura 3 apresenta a distribuição das produções acadêmicas por status jurídico. 
Figura 3 - Distribuição dos artigos por universidade.

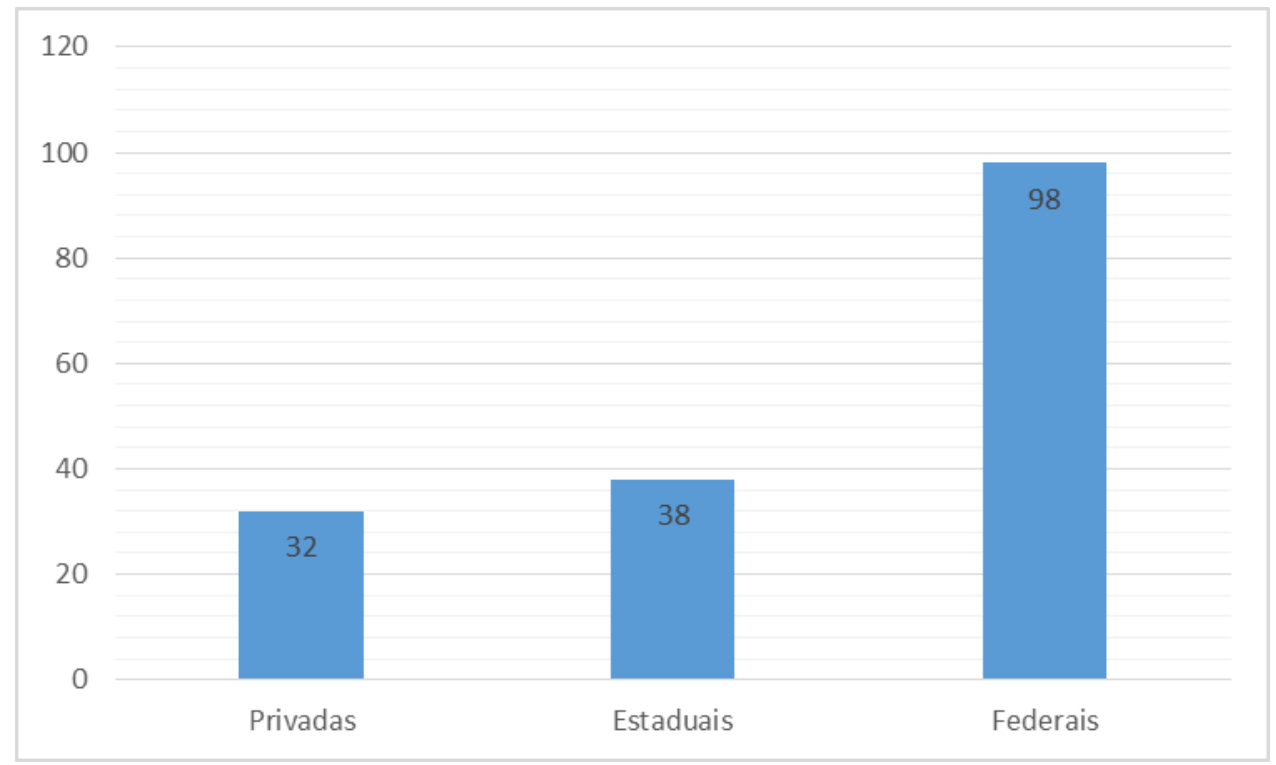

Fonte: Elaboração própria.

Ao analisarmos as distribuições das produções acadêmicas encontradas por status jurídico, verificamos que a maioria das teses e dissertações (58\%) foram defendidas em universidades federais. Estes dados corroboram com os dados do Sistema de Informações Georreferenciadas da Coordenação de Aperfeiçoamento Pessoal de Nível Superior - GEOCAPES (CAPES, 2015). De acordo com a CAPES, atualmente há 2.230 (57\%) programas de pós-graduação em universidades federais, 931 (23,8\%) em universidades estaduais e 715 (18,3\%) em universidades particulares ${ }^{3}$. É importante destacar que as teses e dissertações analisadas estavam vinculadas, em sua maioria, aos programas da área de Educação, Ensino e Engenharia.

\section{Considerações finais}

O panorama brasileiro em relação às produções acadêmicas que versam sobre objetos de aprendizagem revela, por meio de 168 teses e dissertações, que as temáticas predominantes estão relacionadas aos temas: Engenharia de Software, Ensino de Matemática, Ensino Superior, Ensino de Física e Repositórios, sendo que no ano de 2012

\footnotetext{
${ }^{3}$ Os dados da CAPES apontam que há 29 programas de pós-graduação em universidade municipais, no entanto, nenhuma produção acadêmica analisada nesta pesquisa estava vinculada a estas universidades.
} 
observa-se um ápice em relação ao número de produções defendidas. Em relação ao nível de ensino, constatamos que a maioria das produções encontradas são dissertações de mestrado, e que o maior número de produções defendidas concentra-se nas instituições de ensino federais.

Embora reconheçamos que são necessárias investigações sobre interface, usabilidade, linguagem de programação e demais aspectos explorados pela área da engenharia de software, defendemos que não basta termos recursos excepcionais, do ponto de vista tecnológico, se os professores não forem capacitados para utilizar os mesmos, uma vez que boa parte dos professores que atuam na educação básica, não apresentam os conhecimentos necessários para utilizar OA e demais tecnologias digitais de maneira intencional e produtiva (RAMOS, 2009; PEDRO; CHACON, 2013; AZEVEDO et al., 2014).

Além disso, há que se expandir a utilização de OA para todas as disciplinas que compõem o currículo escolar, uma vez que estes proporcionam envolvimento, motivação e enriquecem o processo de ensino-aprendizagem. Destaca-se ainda que estes recursos tecnológicos devem ser explorados com todos os estudantes, incluindo aqueles que são público-alvo da educação especial e aqueles que apresentam dificuldades de aprendizagem.

Acredita-se que só alcançaremos a tão discutida inovação educativa quando estudantes e professores forem capazes de utilizar as TDIC de maneira intencional, consciente, criativa, de sorte que tanto corpo docente como discente farão uso desses recursos sempre que os julgarem necessários, tornando-os artefatos pedagógicos de uso diário, no contexto escolar. 


\section{Referências}

AGUIAR, Eliane Vigneron Barreto; FLÔRES, Maria Lucia Pozzatti. Objetos de Aprendizagem: conceitos básicos. In: TAROUCO, Liane Margarida Rockenbach et al. Objetos de aprendizagem: teoria e prática. Porto Alegre: Evangraf, 2014. p. 12-28.

ALMEIDA, Maria Elizabete Biaconcini. Prolnfo: Informática e formação de professores. Brasília: Ministério da Educação, Seed, 2000.

ALTOÉ, Anair; FUGIMOTO, Sonia Maria Andreto. Computador na educação e os desafios educacionais. In: CONGRESSO NACIONAL DE EDUCAÇÃO, IX e ENCONTRO SUL BRASILEIRO DE PSICOPEDAGOGIA, III. Curitiba/PR, 26 a 29 de novembro de 2009. Anais... 2009. Curitiba: PUC, 2009.

ARAUJO, José Carlos Souza. Fundamentos da Metodologia de Ensino Ativa (1890-1931). In: REUNIÃO NACIONAL DA ANPED, 37ª , Florianópolis, 2015. Anais... Florianópolis: UFSC, 2015. Disponível em: <http://37reuniao.anped.org.br/wpcontent/uploads/2015/02/Trabalho-GT02-4216.pdf>. Acesso em: 27 jan. 2017.

AZEVEDO, Nadia Pereira Gonçalves de; BERNARDINO JÚNIOR, Francisco Madeiro; DARÓZ, Elaine Pereira. O professor e as novas tecnologias na perspectiva da análise do discurso: (des) encontros em sala de aula. Linguagem em (Dis)curso - LemD, Tubarão, SC, v. 14, n. 1, p. 15-27, jan./abr. 2014.

BALAN, Ana Maria Osorio Araya; SCHULUNZEN, Elisa Tomoe Moriya; SCHULUNZEN, Klaus; MELQUES, Paula Mesquita. Banco internacional de objetos educacionais: uma ferramenta para auxiliar no processo de ensino-aprendizagem por meio do uso das Tecnologias de Informação e Comunicação (TIC). Etic - Encontro De Iniciação Científica, v. 6, n. 6, 2010. Disponível em:

<http://intertemas.unitoledo.br/revista/index.php/ETIC/article/viewArticle/2609>. Acesso em: 20 out. 2016.

BARBERÀ, Elena; ROCHERA, Maria José. Os ambientes virtuais de aprendizagem baseados no projeto de materiais autossuficientes e na aprendizagem autodirigida. In: COLL, César; MONEREO, Carles. Psicologia da educação virtual: aprender e ensinar com as tecnologias da informação e comunicação. Porto Alegre: Artmed, 2010. p. 157-170.

BARROS, Daniele Melaré Vieira; BRIGHENTI, Maria José Lourenção. Tecnologias da informação e comunicação \& formação de professores: tecendo algumas redes de conexão. In: RIVERO, Cléia Maria; GALLO, Sílvio. A formação de professores na sociedade do conhecimento. Bauru, SP: EDUSC, 2004. p. 125-144.

BELLUZZO, Regina Célia Baptista; FERES, Glória Georges. Tecnologias e a Formação de Leitores: desafios na sociedade contemporânea. In: BARROS, Daniele Melaré Vieira. et al. Educação e tecnologias: reflexão, inovação e práticas. Lisboa: [s.n.], 2011. p. 1-31. 
BUIM ARENA, Dagoberto. As metamorfoses dos modos de ler: da rua para a escola. Revista Passage de Paris. n. 10, p. 114-124, 2015. Disponível em:

http://www.apebfr.org/passagesdeparis/editione2015/articles/pdf/PP10_Dossier8.pdf. Acesso em: 16 set. 2015.

BULEGON, Ana Marli; MUSSOI, Eunice Maria. Pressupostos Pedagógicos de objeto de aprendizagem. In: TAROUCO, Liane Margarida Rockenbach et al. Objetos de aprendizagem: teoria e prática. Porto Alegre: Evangraf, 2014. p. 54-75.

CAPES. Sistema de informações georreferenciadas - distribuição de programas de pósgraduação no Brasil. 2015. Disponível em:

http://geocapes.capes.gov.br/geocapes2/.Acesso em 28 out. 2016.

CARNEIRO, Mára Lúcia Fernandes; SILVEIRA, Milene Selbach. Objetos de Aprendizagem como elementos facilitadores na Educação a Distância. Educar em Revista. Curitiba, Brasil, Edição Especial n. 4, 2014, p. 235-260. Disponível em:

<http://www.scielo.br/pdf/er/nspe4/0101-4358-er-esp-04-00235.pdf>. Acesso em: 10 out. 2016.

CASTELLS, Manuel. A galáxia da internet: reflexões sobre a internet, os negócios e a sociedade. Rio de Janeiro: Zahar, 2003.

CHRISTENSEN, Clayton. Inovação na sala de aula: como a inovação disruptiva muda a forma de aprender. Porto Alegre: Bookman, 2012.

CORDENONSI, Andre Zanki; BERNARDI, Giliane. Ambientes virtuais de ensinoaprendizagem e objetos educacionais: o diálogo mediado por tecnologias na educação superior. Revista Inter-ação. v. 35, n. 2, p. 253-274, 2010. Disponível em: <www.revistas.ufg.br/interacao/article/download/13134/8530>. Acesso em: 27 out. 2016.

DAMACENO, Daniel Ventura; SANTOS, Rosimeire Martins Régis. Objetos De Aprendizagem No Contexto Escolar. Tear: Revista de Educação Ciência e Tecnologia, Canoas, v. 2, n. 2, 2013, p. 1-21. Disponível em:

<http://seer.canoas.ifrs.edu.br/seer/index.php/tear/article/viewFile/140/71>. Acesso em: 25 out. 2016.

GATTI, Daniel Couto. Sociedade informacional e na/alfabetismo digital: relações entre comunicação, computação e internet. Bauru: EDUSC, 2005.

GELLER, Marta; SOBRINHO, Marialina Corrêa; ARAÚJO, Carlos. Desenvolvendo objetos de aprendizagem utilizando um processo adaptado para software educativo. Anais do Computer on the Beach, Florianópolis, 2010. Disponível em:

<http://siaiap32.univali.br/seer/index.php/acotb/article/viewFile/6333/3570>. Acesso em 27 out. 2016.

GOMES, Fabia de Jesus Lima; LIMA, José Valdeni; NEVADO, Rosane Aragon. Avaliando um Objeto de Aprendizagem para TV Digital. Revista Novas Tecnologias na 
Educação (RENOTE). v.7. n. 3, 2009. p. 2-10. Disponível em: <http://seer.ufrgs.br/index.php/renote/issue/view/952>. Acesso em: 25 out. 2016. GÓMEZ, Angel Pérez. Educação na era digital: a escola educativa. Porto Alegre: Penso, 2015.

LAGARTO, José Reis. Inovação, TIC e sala de aula. In: CAVALHEIRI, Alceu; ENGERROFF, Sérgio Nicolau; SILVA, Jolair da Costa. (Orgs.). As novas tecnologias e os desafios para uma educação humanizadora. Santa Maria: Biblos, 2013, p. 133-158.

LEFFA, Vilson. Nem tudo que balança cai: Objetos de aprendizagem no ensino de línguas. Polifonia. Cuiabá, v. 12, n. 2, p. 15-45, 2006. Disponível em:

<http://www.leffa.pro.br/textos/trabalhos/obj_aprendizagem.pdf >. Acesso em: 26 out. 2016.

LÉVY, Pierre. Cibercultura. São Paulo: Editora 34, 1999.

LIMA, Ivan Shirahama Loureiro de et al. Criando interfaces para objetos de aprendizagem. In: PRATA, Carmem Lúcia; NASCIMENTO, Anna Christina Aun de Azevedo. Objetos de aprendizagem: uma proposta de recurso pedagógico. Brasília: MEC, SEED, 2007. p. 39-48.

LIMA, Marcos Vinicius de Andrade et al. Disponibilizando Objeto de Aprendizagem OBAMC e seus Recursos na TV Digital com Web Service. Laclo. v. 4, n. 1, 2013. p. 1-6. Disponível em: <http://www.laclo.org/papers/index.php/laclo/article/view/110/103>. Acesso em: 25 out. 2016.

MATTAR, João. Games em educação: como os nativos digitais aprendem. São Paulo: Pearson Prentice Hall, 2010.

MELO, Diógenes Maclyne Bezerra de; SILVA, Kátia Cilene da. Jogos digitais e objetos de aprendizagem no ensino da matemática. In ENCONTRO REGIONAL DE EDUCAÇÃO MATEMÁTICA, III, Rio Grande do Norte, 2011. Anais... Rio Grande do Norte, 2011. Disponível em: <http://www.pucrs.br/famat/viali/tic_literatura/artigos/objetos/CC_Melo_e_Silva.pdf>. Acesso em: 24 out. 2016.

MORAN, José. Mudando a educação com metodologias ativas. In: SOUZA, Carlos Alberto; MORALES, Ofelia Elisa Torres (Org.) Convergências midiáticas, educação e cidadania: aproximações jovens. PG: Foca Foto-PROEX/UEPG, 2015. p. 15-33.

OLIVEIRA, Fátima Inês Wolf; GASPARETTO, Maria Elisabete. Los recursos que las tecnologias aportan al professorado de apoyo educativo especializado. In: HEREDERO, Eladio Sebastián; GIROTO, Claudia Regina Mosca; MARTINS, Sandra Eli Sartoreto de Oliveira. La formación del profesorado para la atención a la diversidade em Brasil Y Espanã. Alcalá de Henares: Servicio de Publicaciones de la UAH, 2013. p. 141-166.

OMOTE, Sadao. Produção Acadêmica em Educação Especial. In: OMOTE, Sadao; OLIVEIRA, Anna Augusta Sampaio; CHACON, Miguel Claudio Moriel. (Orgs.). Ciência e 
conhecimento em educação especial. São Carlos: Marquezine \& Manzini: ABPEE, 2014. p. 125-134.

PALFREY, John; GASSER, Urs. Nascidos na era digital: entendendo a primeira geração dos nativos digitais. Porto Alegre: Artmed, 2011.

PAULO, Andrea Barbosa Delfini.; RIBAS, Cíntia Cargnin Cavalheiro; KNAUT, Michelle Souza Julio. A utilização de objetos de aprendizagem no processo de ensino-aprendizagem da EAD: um estudo sobre o uso de jogos virtuais. Revista Eletrônica do Curso de Pedagogia das Faculdades OPET, v. 1, n. 1, p. 1-11, 2015. Disponível em:

<http://www.opet.com.br/faculdade/revista-pedagogia/pdf/n8/artigo-1.pdf >. Acesso em: 27 out. 2016.

PEDRO, Ketilin Mayra; CHACON, Miguel Claudio Moriel. Softwares educativos para alunos com Deficiência Intelectual: estratégias utilizadas. Revista Brasileira de Educação Especial. v. 19, n. 2, p. 195-210, 2013.

PERES, Rosa Maria da Silva; PETITTO, Sônia. A Tecnologia Assistiva na inclusão de alunos com deficiência: um desafio para os professores. In: POKER, Rosimar Bortolini; NAVEGA, Marcelo Tavella; PETITTO, Sônia. (Orgs.) Acessibilidade na escola inclusiva: tecnologias, recursos e o atendimento educacional especializado. Marília: Oficina Universitária, 2012. p. $163-182$.

PESCADOR, Cristina. Alunos nativos digitais e professores imigrante digitais. In: SOARES, Eliana Maria do Sacramento; PETARNELLA, Leandro. (Org.). Cotidiano escolar e tecnologias: tendências e perspectivas. Campinas: Editora Alínea, 2012. p. 15-30.

RAMOS, Daniela Karine. A formação de professores para o uso das tecnologias: um mosaico de concepções e emoções. Revista Novas Tecnologias na Educação. v. 7, n. 1, p. 1-11, 2009. Disponível em: <http://seer.ufrgs.br/index.php/renote/article/view/14030/7920>. Acesso em: 15 dez. 2016.

REATEGUI, Eliseo; BOFF, Elisa; FINCO, Mateus David. Proposta de diretrizes para avaliação de objetos de aprendizagem considerando aspectos pedagógicos e técnicos. Novas

Tecnologias na Educação. v. 8, n. 3, 2010. p. 1-10. Disponível em: <www.seer.ufrgs.br/renote/article/download/18066/10653>. Acesso em: 25 out. 2016.

RODRIGUES, Alessandra Pereira; BEZ, Marta Rosecler; KONRATH, Mary Lúcia Pedroso. Repositórios de objetos de aprendizagem. In: TAROUCO, Liane Margarida Rockenbach et al. Objetos de aprendizagem: teoria e prática. Porto Alegre: Evangraf, 2014. p. 102-138.

SABBATINI, Marcelo. Reflexões críticas sobre o conceito de objeto de aprendizagem aplicado ao ensino de ciências e matemática. Revista de Educação Matemática e Tecnológica Iberoamericana. v. 3, n. 3, 2012. p. 1-36. Disponível em: <http://www.pucrs.br/famat/viali/tic_literatura/artigos/objetos/Sabatini_Marcelo.pdf >. Acesso em: 25 out. 2016. 
SANTAELLA, Lucia. Navegar no ciberespaço: o perfil cognitivo do leitor imersivo. São Paulo: Editora Paulus, 2004.

SANTAROSA, Lucila Maria Costi; CONFORTO, Débora. Formação de professores em tecnologias digitais acessíveis. Porto Alegre: Evangraf, 2012.

SCHMITT, Marcelo Augusto Rauh; TAROUCO, Liane Margarida Rockenbach; RODRIGUES, Alessandra Pereira; VIDEIRA, Jonathan Alba. Depósito de objetos de aprendizagem em repositórios a partir da integração com ambientes virtuais de aprendizagem. Novas Tecnologias na Educação, v. 11, n. 3, p. 1-10, 2013. Disponível em: <http://seer.ufrgs.br/index.php/renote/article/viewFile/44359/28475>. Acesso em: 27 de out. 2016.

SILVA, Edna Lúcia da.; CAFE, Ligia.; CATAPAN, Araci Hack. Os objetos educacionais, os metadados e os repositórios na sociedade da informação. Ci. Inf. [online]. v. 39, n. 3, 2010 p. 93-104. Disponível em: <http://dx.doi.org/10.1590/S0100-19652010000300008>. Acesso em: 25 out. 2016.

VEEN, Wim; VRAKKING, Ben. Homo zappiens: educando na era digital. Porto Alegre: Artmed, 2009.

WILEY, David. Learning object design and sequencing theory. Unpublished doctoral dissertation, Brigham Young University. 2000. Disponível em <http://www.reusability.org/read/chapters/wiley.doc>. Acesso em 7 ago. 2016.

Recebido em: 09/11/2016 Revisões requeridas: 15/05/2017 Aprovado em: 27/06/2017

Universidade do Estado de Santa Catarina - UDESC Programa de Pós-Graduação em Educação - PPGE Revista Linhas

Volume 19 - Número 40 - Ano 2018 revistalinhas@gmail.com 